\title{
How to Present a Poster in a Conference?
}

If you can't make it good at least make it look good.

-Bill Gates, American Software Developer (1955-)

\subsection{What Is the Importance of a Poster Presentation?}

Once your scientific experiment has finished you need to tell the world about its importance [1]. The usual ways are by writing a manuscript and sending it to a peerreviewed journal, by giving a slide presentation at a conference or by the way of a poster presentation at a conference. There are usually workshops held in conferences about how to publish papers. However, little consideration is paid to how to present a good poster. This is also a common method of presenting your work, at a conference and needs to be given importance [2].

\subsection{How to Start Preparing for a Poster Presentation?}

The making of a poster starts with the acceptance of the abstract by the scientific committee of the conference. They will then separate the papers according to the importance of the subjects into those selected for oral presentations or traditional poster presentations. This letter of acceptance is the first step from which the journey to prepare the poster begins [3]. 


\subsection{What Are Important Facts to Know Before You Start a Poster Presentation?}

You should learn some preliminary facts about poster presentations before starting your project. These include [4]:

- About $30 \%$ of posters are cluttered or 'sloppy'.

- About $20 \%$ have fonts that are too small to read from a distance.

- In about $38 \%$ the research question cannot be located after a one-minute survey.

There is another interesting fact called the ' $10 \times 10$ rule for poster presentations', i.e., the average attendee spends only 10 seconds to scan the poster as he/she strolls in from a distance of 10 feet. It is imperative therefore that the poster should be eyecatching and attract a potential reader to come close to it. Thus, poster making combines both the science and the art of scientific presentations [5].

\subsection{What Are the Stages of a Poster Presentation?}

The stages are the planning of the contents, organizing the data, drafting, and finally printing the poster. The final endorsement comes during the interaction with the audience as to how well you have been able to 'sell' your work and defend it at the same time.

The various steps for poster presentation are described below:

\subsubsection{Step 1: Planning}

Simplicity is the key mantra for a poster. A person does not spend more than a few seconds gazing at the poster, so there should be a minimum of clutter and a maximum of graphics.

1. The information provided by the conference organizers is vital at this stage. They usually specify details such as the poster size, poster number and on which day, place, and time it may be displayed.

2. Go through the abstract and make sure it contains all the necessary information.

3. Check all the data and tables and figures.

4. There are many paid and unpaid sites that provide templates for poster presentations (Table 37.1). The ideas may be borrowed from them but be creative and use your own ideas as well.

Table 37.1 Paid/free sites for poster template

\begin{tabular}{l|l}
\hline Free sites for poster template & Paid sites for poster template \\
\hline https://www.freepik.com & https://graphicriver.net \\
\hline https://www.postermywall.com & https://in.pinterest.com \\
\hline https://pngtree.com/poster-templates & https://www.canva.com \\
\hline
\end{tabular}




\subsubsection{Step 2: Organization of the Poster}

A poster has been compared to the story of a movie. It should contain the setting of the main plot (research question), methods, climax (results), and the ending (conclusions). Figure 37.1 shows how to organize a poster into various heading.

\subsubsection{Step 3: Printing of the Poster}

Before this stage, it is always better to show a draft of the poster to a friend or senior colleague who has more experience. Their inputs at this stage can be very useful.

There are two types of papers available for printing. Glossy paper is expensive but it is durable. There is glare as the light reflection can make it difficult to see the poster from a particular angle. There is, however, better resolution of clinical photographs, histopathology, and radiology illustrations. In comparison matte paper does not reflect light, is more economical but less durable, and also provides less resolution for illustrations [2].

\subsection{How Should the Material Be Placed in the Poster?}

A poster has three main components $[5,6]$ :

- Main text

- Illustrations such as statistical graphs, flow diagrams, and photographs

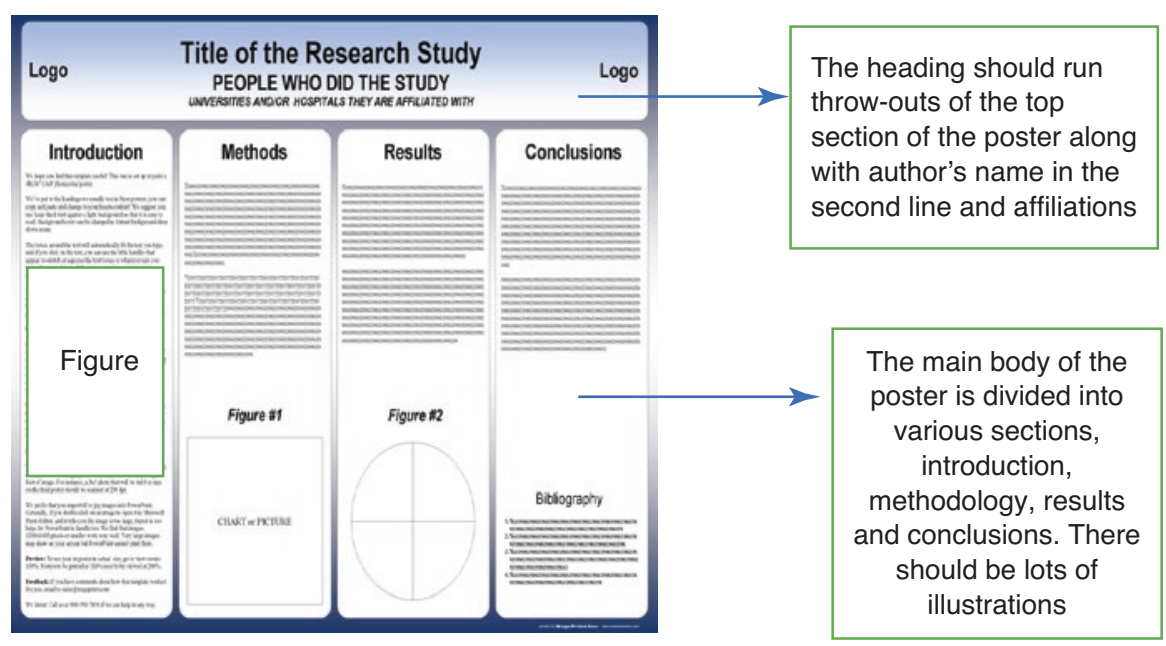

Fig. 37.1 Organization of the poster 


\subsection{Background}

Make a plan for the poster and fix a space for each component [7].

- The heading appears in the uppermost part of the poster. The title should be readable from at least 2 metres away. The names of the authors and their affiliations should also come under the heading [4].

- Introduction should be brief and should be 3 to 5 lines and appear at the upper left portion of the poster.

- Research question, aims, methodology, and results need to be placed subsequently. Do not repeat any data. If possible, use more space for tables and results.

- Illustrations are important components of a poster and add life to it.

- The conclusions should appear at the lower right portion of the poster.

\subsection{What Should Be the Font Size of the Text in a Poster?}

- The main content of the poster should be made double-spaced with a left-sided justification.

- A text with its left side even and right side jagged is easiest to read.

- The font size is important. Posters should be legible from a distance of about 2 metres [8].

- In general, use font sizes proportional to the subheading in the poster.

- The title should have the largest font and should be bold and at least 72 points.

- The subheading is the next largest and should be at least 48 points and bold.

- The text of the body font should be at least 24 points.

- Both landscape or portrait layouts are good for a text poster.

- You need to be consistent in using fonts. Only one type should be used throughout the poster.

- Bold headings stress importance. The other ways of doing this are by highlighting or underlining, or using different colours. A text in italics is difficult to read from a distance.

\subsection{What Should Be the Word Count in a Poster?}

The success of a poster is directly related to the "clarity of the illustrations and tables and viewing a poster should be a visual feast'. [2] The total word count of the poster text should be between 300 and 800 words. More important than the word count are the illustrations. A self-explanatory graph should govern the poster. The text should supplement the photographs wherever possible. Less text is better, be innovative in the poster, in the placement of the text, and a light background stands out (Fig. 37.2). 
Effect of smoking in young males on complete blood counts.

ABC........The Ganga Ram Institute of Postgraduate Medical Education and Research, Sir Ganga Ram Hospital

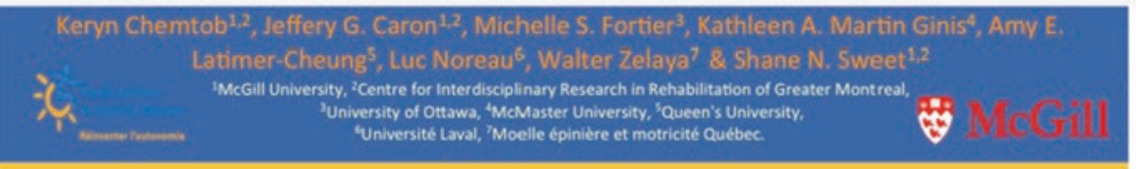

IntroduCtion
- Adults with Spinal Cord Injury (SCI) report lower quality of life than the
general population (QOL) (Post et al., 2012)
- Participation in activities of daily living influences QOL in adults with
SCI (Whalley Hammell, 2007)
- Peer mentorship has been shown to increase participation in daily
activities and quality of life for adults with SCI (Sherman et al., 2004)
- Few studies have examined how and why peer mentorship
experiences have impacted participation

Objectives:

- Explore the SCI peer mentees' perceptions of their experiences with peer mentorship and understand how mentees believed their peer mentors fostered enhanced participation

Methods
- 13 adults with $\mathrm{SCl}$ who received peer-mentorship participated in a
semi-structured interview
- 9 men and 4 women; $49.3,10.5$ years old, $54 \%$ with paraplegia
- Interviews inductively analyzed using Braun and Clarke's (2013)
guidelines for thematic analysis

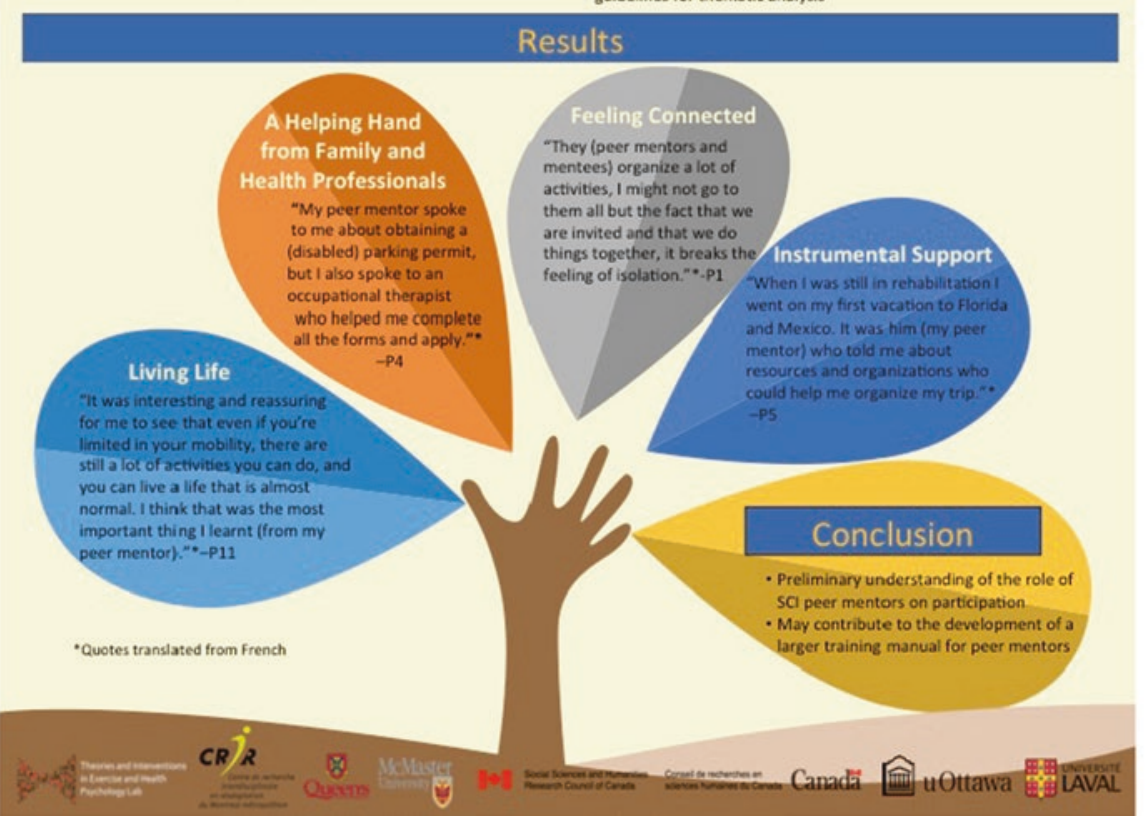

Fig. 37.2 Word count in a poster 


\subsection{How Should the Poster Background Look?}

The choice of a background colour depends on the presenter. Softer pastels or greys look fine. They can be easily viewed for a long time and are also ideal for graphics and photographs. Dark backgrounds should be avoided, as the graphics do not stand out against them. Backgrounds with a graded texture make a poster look too busy.

\subsection{What Are the Important Considerations While Making a Poster?}

- Graphic illustrations should be visible easily from a minimum 2 metres. Do not use more than 3 colours in a poster.

- Avoid photographs less than $5 \times 7$ inch as they may be difficult to see.

- All figures should have legends.

- All photographs should be at least 300 dpi for clarity and good resolution.

- Cropping all unwanted details from photographs helps to depict what you want to show.

- Having a thin outline around photographs, helps them to look prominent.

- The colour of graphs should match with the poster.

- Do not use copyright images for poster presentation.

\subsection{What Are the Limitations of Posters?}

The poster presentation occurs in a calmer environment than an oral presentation. It also encourages much more individual interaction between the author and viewer than an oral presentation. However, it has many drawbacks. Firstly, the reach of posters is limited to a few delegates compared to an oral presentation. Secondly, the interaction may need to be repeated many times with different attendees. Thirdly, any routine or inconsistent conclusions cannot be debated in a group.

\subsection{How Should You Store and Transport a Poster?}

The packing and carriage can be done in cardboard tubes or plastic rolls. Identification details should also be mentioned on the tube to recover it if it gets lost. If the poster is to be reused then using a thick quality of paper with lamination along with a box will increase its life.

\subsection{How Should You Display the Poster?}

Although the organizers usually provide pins or tape at the conference venue, it is always better to carry these with you. Also, carry a few A4 printouts for distribution. 


\subsection{What Happens During the Interaction?}

The interaction during a poster presentation is a better way of communication than an oral presentation as it is only between two individuals. The time for displaying the poster and for interaction is usually given in the letter of acceptance. If the scientific content of the paper is good then the poster is shortlisted for a special poster tour. There is often an award given to the best poster for its overall content, aesthetics, and interaction of the author with the referee.

\subsection{What Are the Types of Poster Presentations?}

By convention, a poster has to be printed on paper. However, the demand for an electronic poster format is increasing in many conferences. The e-poster is inexpensive, it saves paper, is quicker, has better colours, and is easy to carry. It uses the PowerPoint format or multimedia, which is more versatile. The impact of an e-poster is greater as 3D animation and surgical technique videos can be loaded and it is visually appealing. This has revolutionized poster sessions as science has become more colourful and vivid. In this COVID era the majority of conferences except for posters are in the e-format. Smartphones and tablets are new generation devices that have paved the way towards the electronic format of poster presentation.

Examples of good and bad posters are shown in Figs. 37.3 and 37.4.

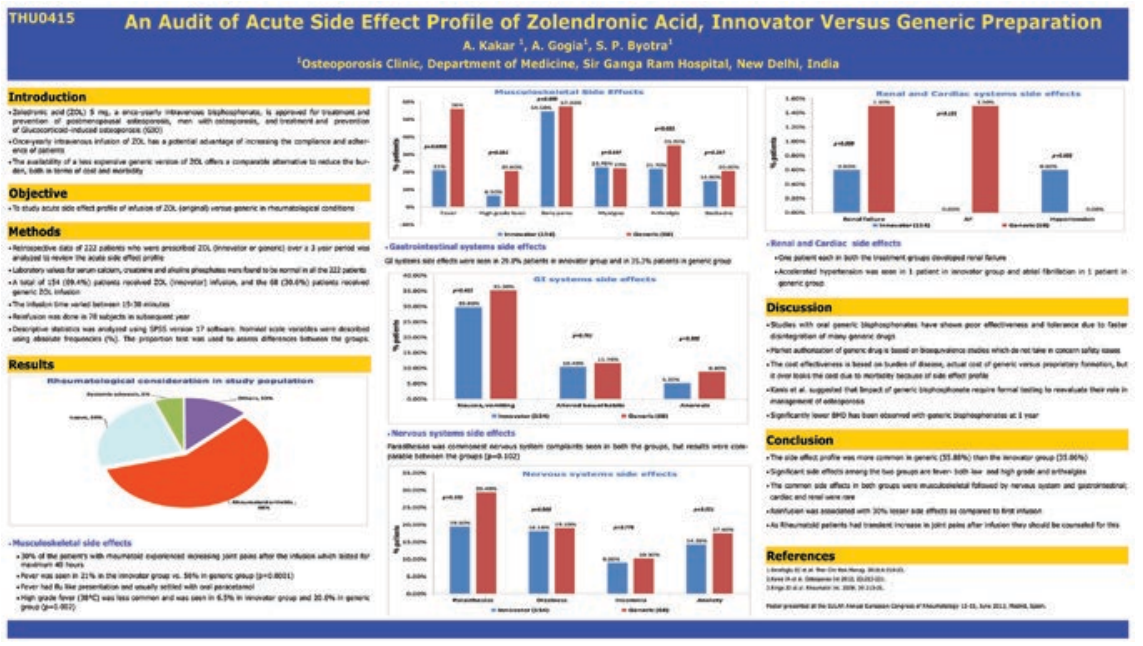

Fig. 37.3 Balance of text with graphs 
Fig. 37.4 Too much data, balance between text and figure is missing

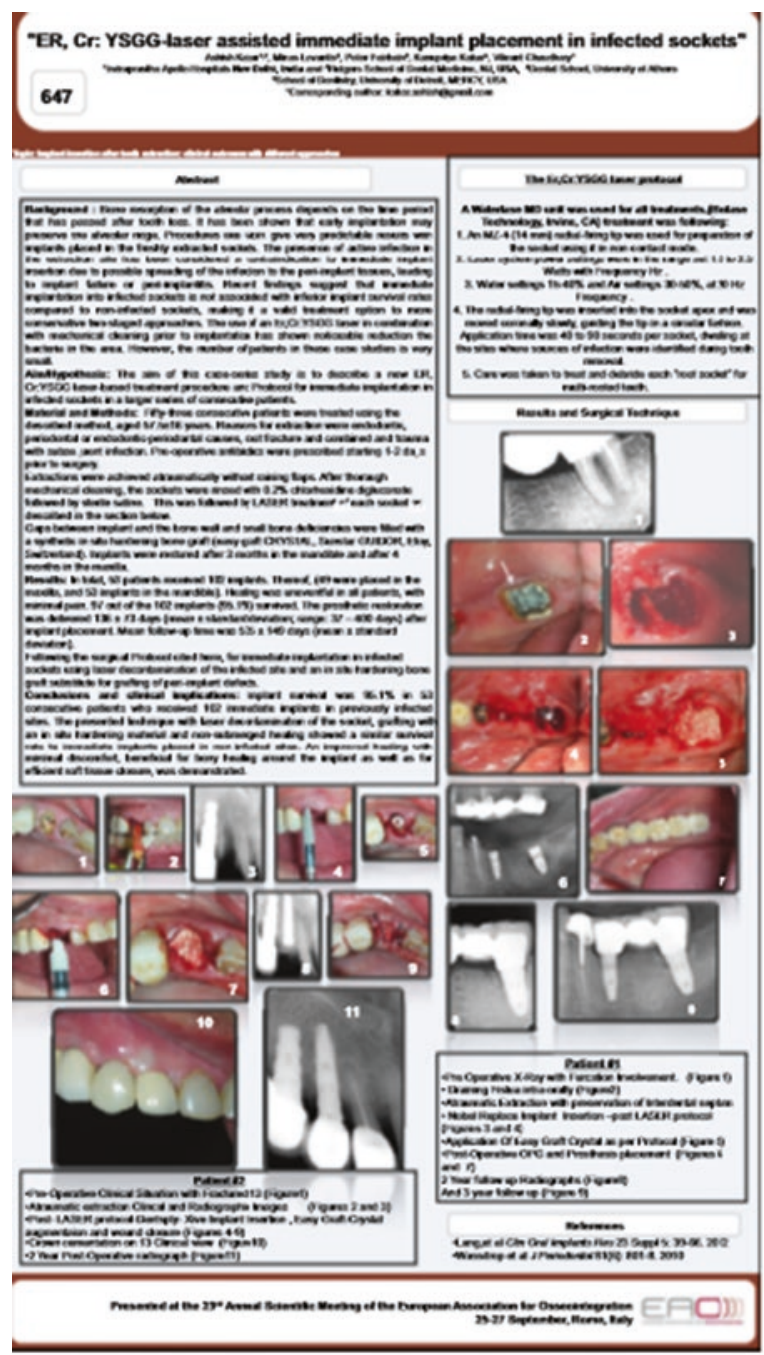

\subsection{Conclusions}

- A poster presentation is a combination of art and science.

- It is an effective way to communicate scientific work.

- It has many stages like planning, organization, printing, and transportation.

- The interaction session with the viewer is important during the display and may yield new ideas.

- The e-posters are a new and powerful technique being used in many conferences. 
- Analyse study data

- Short list important / interesting observations and material illustrations, graphs, charts, photographs

- Read details about poster presentation from conference web site

- Title: Most important 'Be innovative'

- Author and affiliation

- Introduction - brief outline

- Problem: what is the scientific question to be tested?

- Methods and material - brief discription, use algorithm, flow chart

- Results: outcome measures

- Conclusion: summary

- References (minimum)

- Acknowledgement

- Contact information

- Decide general lay out and placement of text and graphics

- Colour scheme

- Font

- Material: paper / flexi paper

- Cardboard roll / Storage box

- Lamination of paper roll

Fig. 37.5 Flow chart of how to proceed with a poster

\subsection{What Are the Various Steps in Making a Poster?}

The various steps are given in Fig. 37.5.

\section{References}

1. Gundogan B, Koshy K, Kurar L, Whitehurst K. How to make an academic poster. Ann Med Surg (Lond). 2016;11:69-71.

2. Chopra R, Kakar A. The art and science of poster presentation in a conference 2014; 4:294-304.

3. Tasker F. How to make a scientific poster? Stud BMJ. 2013;21:1297.

4. Presentation. A MEE guide no 40. Med Teach. 2009;31:319-21.

5. Boullata JI, Mancuso CE. A "How to" guide in preparing abstract and poster presentation. Nutr Clin Pract. 2007;22:641-646.

6. Miller JE. Preparing and presenting effective research posters. Health Serv Res. 2007;42:311-28.

7. Erren TC, Bourne PE. Ten simple rules for a good poster presentation. PLoS Comput Biol. 2007;3:e102.

8. Larive $\mathrm{CK}$, Bulsha $\mathrm{E}$. ABCs of teaching analytic science: tips for effective poster presentation. Anal Bioanal Chem. 2006;385:1347-9. 
Open Access This chapter is licensed under the terms of the Creative Commons Attribution 4.0 International License (http://creativecommons.org/licenses/by/4.0/), which permits use, sharing, adaptation, distribution and reproduction in any medium or format, as long as you give appropriate credit to the original author(s) and the source, provide a link to the Creative Commons license and indicate if changes were made.

The images or other third party material in this chapter are included in the chapter's Creative Commons license, unless indicated otherwise in a credit line to the material. If material is not included in the chapter's Creative Commons license and your intended use is not permitted by statutory regulation or exceeds the permitted use, you will need to obtain permission directly from the copyright holder. 